\title{
APONTAMENTOS PARA A COMPREENSÃO DO SISTEMA DE COLETA SELETIVA ${ }^{1}$
}

\author{
Karla Handressa Castro de Oliveira ${ }^{2}$ \\ Rogerio Eriks da Silva ${ }^{3}$
}

Edilene Mayumi Murashita Takenaka ${ }^{4}$

\section{RESUMO}

O presente trabalho tem como principal objetivo, analisar o sistema de coleta seletiva, cujo princípio trata da separação e destinação final correta dos seus resíduos sólidos buscando a minimização dos impactos ambientais causados pela má disposição dos mesmos. A metodologia utilizada para o desenvolvimento da pesquisa foi o levantamento bibliográfico consultando artigos e livros sobre o histórico do assunto, adotando o método dedutivo para sua conclusão. Destacamos ainda, as maneiras adotadas para a realização da coleta seletiva, os problemas enfrentados e a questão dos usuários junto a este tema. Concluímos que, por mais problemas que a coleta seletiva possa enfrentar no seu funcionamento, ela é fonte de renda para dezenas de famílias e mostra-se eficiente quanto à minimização de resíduos lançados inadequadamente, o que contribui para o gerenciamento dos resíduos sólidos das localidades municipais.

Palavras-chave: Resíduos Sólidos. Coleta Seletiva. Disposição Final.

\section{APPOINTMENTS TO COMPREHENSION OF THE SELECTIVE GATHERING SYSTEM}

\footnotetext{
${ }^{1}$ Trabalho desenvolvido a partir de discussões realizadas durante a disciplina "Políticas públicas ambientais e gerenciamento de resíduos sólidos", ministrada pela professora Dra. Edilene Mayumi Murashita Takenaka, do curso de Mestrado em Meio Ambiente e Desenvolvimento Regional MMADRE/UNOESTE.

${ }^{2}$ Bacharel em Direito e Especialista em Direito e Processo do Trabalho. Aluna especial do curso de Mestrado em Meio Ambiente e Desenvolvimento Regional - MMADRE/UNOESTE handressa.pit@hotmail.com

${ }^{3}$ Bacharel em Administração e Especialista em Gestão Estratégica de Marketing e Negócios. Aluno especial do curso de Mestrado em Meio Ambiente e Desenvolvimento Regional - MMADRE/UNOESTE -rogério.eriks@gmail.com

${ }^{4}$ Docente da disciplina Políticas Públicas Ambientais e Gerenciamento de Resíduos Sólidos do curso de Mestrado em Meio Ambiente e Desenvolvimento Regional - MMADRE/UNOESTE edilene@unoeste.br
} 


\begin{abstract}
The present work has as main goal, to analyse the seletive gathering system, whose principle refers of the separation and the right final allocation of your solid combings, seeking the enviroment impacts minimization caused by the bad disposition of them. The methodology used for the development of the search was a bibliography clearance consulting articles and books about the historic of the subject, adopting the deductive method for your conclusion. We still enphasize that the adopted ways for the seletive gathering realization, the faced problems and the users issue with this theme. We conclude that, for more problems that the gathering seletive can face on your operation, it is a income source to dozens familys and shows up efficient how minimization of launched inadequate combings, which contributes for the solid combings management to municipal locations.
\end{abstract}

Key-words: Solid Combings. Selective Gathering. Final Disposition.

\title{
NOTAS A LA COMPRENSIÓN DEL SISTEMA DE RECOGIDA SELECTIVA
}

\section{RESUMEN}

Este estudio tiene como objetivo analizar los sistemas de recogida selectiva, el principio es la correcta separación y eliminación de residuos sólidos buscando minimizar los impactos ambientales causados por la mala disposición de los mismos. La metodología utilizada para el desarrollo de la investigación fue la literatura se refiere a artículos y libros sobre la historia de la materia, adoptando el método deductivo para su finalización. También señalamos las formas adoptadas para llevar a cabo la recogida selectiva, los problemas que enfrentan y la cuestión de los usuarios con este problema. Llegamos a la conclusión de que, para la mayoría de los problemas que la recogida selectiva puede enfrentar en su funcionamiento, es una fuente de ingresos para decenas de familias y muestra eficiente como la minimización de los residuos liberados de forma inadecuada, lo que contribuye a la gestión de los residuos sólidos desde ubicaciones municipales.

Palabras clave: Residuos Sólidos. Recogida Selectiva. Disposición Final.

\section{INTRODUÇÃo}

O crescimento de bens de consumo cada dia mais descartáveis são decorrentes de fatores como o aumento populacional, qualidade de vida e de forma geral um maior poder aquisitivo advindo da estabilidade econômica conquistada pelo brasileiro nos últimos anos. O aumento de consumo gera um grande volume de resíduos sólidos, que são descartados de maneira errônea, ocasionando impactos ao meio ambiente. Frente a esta problemática, os municípios brasileiros buscam 
implantar formas de gerenciamento de tais resíduos como uma alternativa para a minimização desta questão.

Com a finalidade de reduzir os impactos provocados pela disposição final inadequada nas localidades, encontrou-se como alternativa a implantação do sistema de coleta seletiva dos resíduos sólidos através da criação de instituições específicas para realização deste serviço.

O presente trabalho justifica-se pela necessidade de analisar o serviço desenvolvido por tais instituições e tem como objetivo realizar apontamentos de questões para melhor compreensão do sistema de coleta seletiva.

Esta pesquisa desenvolveu-se a partir de fundamentação teórica através de levantamento bibliográfico realizado em consultas a artigos e livros sobre o assunto, adotando o método dedutivo para sua conclusão.

\section{APONTAMENTOS SOBRE O TEMA}

\subsection{Lixo ou Resíduos Sólidos}

Segundo Dias (2004, p.18) "A palavra lixo não deve ser mais utilizada, pois ela expressava o que não presta, não serve para nada. A cultura do lixo vem desaparecer para dar lugar à cultura dos resíduos sólidos (matéria prima a ser reaproveitada)".

Para Miranda (1995, p.18) a definição de lixo para Organização Mundial de Saúde (OMS) é "qualquer coisa que seu proprietário não quer mais, em um dado lugar e num certo momento, e que não possui valor comercial".

A geração de lixo tem um aumento significativo ocasionado pelo crescimento da população e com os níveis de consumo. Neste contexto, tem-se um dos maiores desafios que é a escassez de locais inadequados para sua disposição (BARTOLOMEU; CAIXETA-FILHO, 2011).

Deste modo entende-se que lixo é somente o que não tem mais utilidade, não podendo ser utilizado de maneira alguma tendo como única alternativa a destinação final. 
A definição de resíduos sólidos segundo a Associação Brasileira de Normas Técnicas, através da NBR 10.004 (2004) é: Resíduos nos estados sólidos e semissólido, que resultam de atividades de origem industrial, doméstica, hospitalar, comercial, agrícola, de serviços e de varrição. Ficam incluídos nesta definição lodos provenientes de sistemas de tratamento de água, aqueles gerados em equipamentos e instalações de controle de poluição, bem como determinados líquidos cujas particularidades tornem inviável o seu lançamento na rede pública de esgotos ou corpos d'água, ou exijam para isso soluções técnicas e economicamente inviáveis em face à melhor tecnologia disponível.

Com base nas definições expressas, entende-se como lixo tudo aquilo que não é possível de ser reutilizado e nem aproveitado tendo apenas como destino o descarte. Os resíduos sólidos, por sua vez podem ter outros fins sendo reaproveitados de alguma maneira e assim voltando à cadeia produtiva. A partir destes conceitos será adotada a terminologia "resíduos sólidos" ao longo do presente artigo.

\subsection{Geração dos Resíduos Sólidos}

De acordo com a Associação Brasileira de Empresas de Limpeza Pública e Resíduos (ABRELPE), nos últimos anos houve um crescimento expressivo na geração de resíduos sólidos superando a taxa de crescimento populacional urbano.

Bartolomeu e Caixeta-Filho (2011) destacam que é extremamente difícil conseguir estimar precisamente a quantidade de geração de resíduos sólidos, mas alguns índices do município conseguem dar a ideia aproximada dos resíduos gerados, dentre estes estão: o tamanho dos municípios em função da população; a atividade produtiva predominante; nível socioeconômico; sazonalidade da ocupação; existência de coleta seletiva e ações governamentais de incentivo a redução na geração de resíduos domiciliares.

Portanto a geração de resíduos sólidos aumenta com o passar dos anos, variando de acordo com os diversos fatores e geram vários problemas com a disposição dos mesmos sendo necessárias técnicas adequadas de disposição final e 
gerenciamento.

\subsection{Disposição Final dos Resíduos Sólidos}

De acordo com Secretaria Estadual do Meio Ambiente (2010, p. 24), "a disposição final deveria ser restrita somente ao rejeito, isto é, à parte inaproveitável dos resíduos sólidos".

A Pesquisa Nacional de Saneamento Básico (PNSB) (2008) ressalta que as regiões onde a disposição dos resíduos sólidos tem proporção maior em lixões são: Nordeste, Norte e Centro-Oeste, enquanto as demais regiões Sul e Sudeste dividem suas destinações em aterros controlados e sanitários.

De acordo com Bidone e Povinelli (1999), os lixões a céu aberto estão presentes em $70 \%$ das cidades brasileiras como método de disposição final de seus resíduos.

Para Jardim (1995, p.76), "lixão é uma forma inadequada de disposição final de resíduos sólidos, que se caracteriza pela simples descarga sobre o solo, sem medidas de proteção ao meio ambiente ou a saúde pública". Ainda segundo o autor uma técnica para se resolver o problema dos lixões a céu aberto é a criação de aterros controlados, pois minimizam os impactos causados ao meio ambiente.

Bartolomeu e Caixeta-Filho (2011, p.35) fala que "aterro controlado é o local de disposição de resíduos sólidos urbanos que utiliza a técnica de recobrimento dos resíduos por uma camada de material inerte".

Estes aterros controlados dispõem os resíduos em valas que são escavadas no solo e recobertas ao final de cada dia de trabalho com terra, cobrindo os resíduos e não deixando-os expostos diretamente ao intemperismo e não permite haver a exalação de odores e a proliferação de vetores, mas pode causar contaminação do lençol freático se estiver muito próximo a superfície.

Mas a técnica mais adequada para disposição dos resíduos sólidos é a de implantação de aterros sanitários. "O aterro sanitário é uma forma de disposição final de resíduos sólidos urbanos no solo, dentro dos critérios de engenharia e normas operacionais específicas, proporcionando o confinamento seguro dos resíduos" 
(BIDONE, POVINELLI, 1999, p.18).

A implantação dos aterros sanitários é a forma mais correta de se dispor os resíduos sólidos, pois apresentam alto índice de confiabilidade por possuir técnicas corretas de engenharia na sua construção e funcionamento.

\subsection{Impactos causados pela disposição inadequada dos resíduos sólidos}

Os resíduos lançados de maneira inadequada geram enormes impactos ao meio ambiente e a saúde das pessoas. Segundo Miranda (1995) são grandes os impactos ambientais causados, pois o lixo é depositado no meio ambiente sem nenhum critério, poluindo o ar através dos gases que pairam da decomposição do lixo, além da presença de odor e fumaça constante e a poluição do solo e da água através do chorume, que penetra no solo deixando o solo inapto para o plantio e atinge as águas subterrâneas e as águas superficiais contaminando-as.

De acordo com Jardim (2005), além dos impactos ambientais a destinação incorreta causa outros tipos de problemas, dentre eles estão:

- Problemas sanitários: fogo, fumaça, odor, proliferação de macrovetores como cachorros, gatos, ratos, urubus, pombos e de microvetores, como as moscas mosquitos, bactérias e fungos;

- Problemas operacionais: ausência de controle de resíduos, de critérios para a disposição de lixo no solo, método de manejo de lixo, falta de cercas e vias de acesso;

- Problemas sociais: a presença de catadores que utilizam os resíduos encontrados como fonte de renda e, muitas vezes, alimentam-se dos restos de comida que encontram ficando expostos a doenças.

Dentre os problemas citados, aqueles que envolvem a preservação ambiental necessitam de respostas e práticas pontuais para garantir a qualidade do meio ambiente que institui fator decisivo para a obtenção de uma melhor qualidade de vida no planeta. Os problemas sanitários e operacionais poderiam ser sanados a partir de um adequado gerenciamento dos resíduos sólidos. 
Entretanto, os problemas sociais são de suma importância quando se diz respeito a destinação incorreta dos resíduos, devido ao elevado número de pessoas que tem sua sobrevivência dependente da catação em lixões expostos as condições de vida desumana e precária.

\subsection{Coleta Seletiva}

De acordo com Miranda (1995), entende-se por coleta seletiva o procedimento de separação na origem, do lixo a ser coletado, em orgânico e inorgânico.

Segundo Jardim (1995), a coleta seletiva tem embasamento na realização da separação na própria fonte geradora dos materiais recicláveis e que podem ser reutilizados mediante acondicionamento.

Para Bartolomeu e Caixeta-Filho (2011) o sistema de coleta seletiva consiste no potencial de reciclagem dos resíduos como papel, papelão, plástico e metal (materiais ferrosos e não ferrosos).

A Secretaria do Meio Ambiente (2010) destaca que a coleta seletiva é composta pelos resíduos recicláveis e é utilizada como uma alternativa de gerenciamento dos resíduos sólidos.

O principal ponto positivo deste gerenciamento é a redução da quantidade de resíduos a serem dispostos em aterro e, um dos fatores importantes para sua eficiência, é a participação da comunidade neste processo, pois é através da população que se realiza o acondicionamento e a segregação dos resíduos na fonte ao separarem os materiais recicláveis dos não recicláveis, também chamados de lixo úmido ou simplesmente lixo, que são compostos por matéria orgânica.

Para Bartolomeu e Caixeta-Filho (2011, p. 25):

O sistema de coleta seletiva se pressupõe que os resíduos sejam triados pelos geradores facilitando o manejo, separação e comercialização pelas cooperativas de reciclagem. Os materiais recicláveis compõem cerca de $40 \%$ dos resíduos sólidos domiciliares, e seu aproveitamento, além de poupar energia, contribui para redução na quantidade e do volume de resíduos que são dispostos em aterros, ampliando a vida útil destes locais de destinação. 
Ainda segundo os autores a coleta seletiva apresenta modelos de classificação, que são: Coleta seletiva com entrega voluntária: situação em que o gerador se desloca até os Postos de Entrega Voluntária (PEV) e deposita os materiais recicláveis em contêineres; Coleta seletiva porta a porta: neste modelo, os materiais recicláveis são separados pelo próprio gerador e os coletores passam recolhendo estes materiais, sem que haja deslocamento do gerador; Coleta seletiva com postos de troca: é realizada pela iniciativa privada e tem como embasamento a troca de resíduos recicláveis por algo que tenha valor monetário semelhante ou correspondente ao valor comercial do resíduo que está sendo trocado.

\subsubsection{Benefícios da coleta seletiva}

Segundo a Secretaria do Meio Ambiente (2007), a coleta seletiva exerce um papel importante para a preservação do meio ambiente, pois por meio dela recuperam-se matérias primas que de outro modo seriam extraídas da natureza.

A coleta seletiva como alternativa de gerenciamento de resíduos sólidos tem como vantagem: a menor exploração de florestas nativas; a redução na extração dos recursos naturais; a diminuição na poluição do solo, água e do ar; a economia de energia no reprocessamento de materiais; a diminuição de custos de produção com o aproveitamento de materiais recicláveis pelas indústrias; a diminuição do desperdício; as melhorias na limpeza e higiene do município; a geração de empregos, renda a partir da criação de cooperativas para fortalecer a comercialização dos materiais recicláveis; a diminuição na disposição de resíduos em aterros e dos impactos ambientais decorrentes; e o prolongamento da vida útil dos aterros sanitários.

\subsubsection{Associações e cooperativas}

Segundo o Serviço Brasileiro de Apoio às Micro e Pequenas Empresas (SEBRAE), as cooperativas tem como donos e beneficiários os próprios cooperados, enquanto nas associações os associados não são propriamente seus "donos".

Para Bartolomeu e Caixeta-Filho (2011) o sistema de separação dos materiais 
recicláveis cumpre um papel importante na gestão dos resíduos sólidos sobre vários aspectos entre eles: estimula o hábito de separação na própria fonte geradora; promove a educação ambiental voltada para diminuir o consumo e o desperdício; gera trabalho, renda para cooperativas e associações de catadores de materiais recicláveis.

Segundo o mesmo autor o sistema de coleta seletiva tem como um dos seus objetivos sociais a inserção dos catadores da coleta informal na sociedade, visando à emancipação econômica dos mesmos e a ampliação de serviços, com inclusão social e melhores condições de vida através da criação de cooperativas e associações.

De acordo com Santos (2011) as principais políticas e ações do governo para a inserção de organizações de catadores no ciclo econômico no Brasil são: a criação da categoria de catador de material reciclável através do Ministério do Trabalho e Emprego, no Cadastro Brasileiro de Ocupações (CBO) com o reconhecimento da atividade e os mesmos direitos de um trabalhador autônomo; a elaboração de Planos de Inclusão Social como um instrumento de planejamento de inclusão; a criação de linhas de financiamento para os municípios que realizarem a implantação do sistema de tratamento e disposição final adequados de seus resíduos sólidos; a formação de parcerias entre universidades, prefeituras na capacitação de equipes municipais, Organizações não Governamentais e de associações de catadores para a realização de projetos de captação de recursos para gestão integrada dos resíduos; o incentivo e apoio as organizações de catadores com os gestores implantando o sistema de coleta seletiva e priorizando as políticas sociais de inclusão para assegurar a complementação de renda dos catadores do sistema de coleta seletiva.

A forma de organização em cooperativas e associações possibilita aos catadores um maior poder de barganha de seus materiais recicláveis junto ao poder público e com as indústrias, pois criam um canal de venda direta com a obtenção de melhores preços. (MEDINA, 2000; RODRIGUEZ, 2004 apud PAULA e PINTO, 2010).

As cooperativas e associações realizam um papel significativo no desenvolvimento e no crescimento da economia de um país, pois com o trabalho que realizam geram fonte de renda; contribui para a saúde pública; para o sistema de saneamento, para a sustentabilidade do meio ambiente por causa da minimização de 
matéria prima utilizada; conservação de recursos e geração de energia.

A criação de cooperativas e associações formadas por ex-catadores oriundos dos lixões municipais podem ser consideradas como uma alternativa aos problemas sociais causados pela disposição inadequada dos resíduos sólidos .

\subsection{Reciclagem}

Para Jardim (1995), reciclar é o resultado de diversas atividades em que os materiais que se tornariam lixo ou estão no lixo, são coletados e separados para serem utilizados como matéria prima na manufatura de bens, feitos anteriormente apenas com matéria prima virgem.

Segundo Dias (2004), a importância de reciclar está como no exemplo do papel que em cada tonelada de reciclado 17 árvores são preservadas; 26 litros de água são economizados; 27 kg de poluição do ar não são produzidos; a reciclagem poupa energia elétrica; e reduz a quantidade de resíduos aproximadamente de um terço nas suas disposições finais.

De acordo com a Secretaria do Meio Ambiente (2007), reciclar é diferente de separar, pois consiste no ato de transformar os materiais por meio de processo industrial ou artesanal, ressaltando que a separação ou triagem dos resíduos sólidos de nada adianta senão tiverem como destino o encaminhamento para a reciclagem.

Após serem separados, cada material por categoria, são prensados e posteriormente, comercializados para as empresas de transformação, que se utiliza dessa fonte de matéria-prima para a produção de suas mercadorias.

Segundo o Compromisso Empresarial para Reciclagem (CEMPRE), os materiais recicláveis podem ser encontrados no nosso dia a dia de diversas formas, tais como:

- Papel: presente nas caixas de papelão ondulado, jornais e revistas, fotocópias, folhas de caderno, envelope, formulários de computador, provas, caixas em geral, rascunhos, aparas de papel, cartazes velhos e papel de fax;

- $\quad$ Plástico (dividido em vários tipos): Polietileno Tereftalado (PET) frascos de refrigerantes, produtos farmacêuticos, produtos de limpeza, mantas de 
impermeabilização e fibras têxteis, entre outros; Polietileno de Alta Densidade (PEAD) - embalagens de cosméticos e frascos de artigos químicos e de limpeza dentre outros; Policloreto de Vinila (PVC) - frascos de água mineral, calçados, encapamentos de cabos entre outros; Polietileno de Baixa Densidade (PEBD) embalagens de alimentos, os sacos de lixo e rótulos de diversos brinquedos e outros; Poliproprileno (PP) - embalagens e potes alimentícios, seringas descartáveis, entre outros; Poliestireno (PS) - copos descartáveis, placas isolantes, aparelhos de som e televisão, material escolar e outros como plásticos especiais e de engenharia, CDs, eletrodomésticos;

- Vidros: presentes nas janelas, automóveis, fogões, tigelas, copos, lâmpadas, vidros de laboratório;

- Metais: os ferrosos - latas de alimentos e bebidas e latas de aço; os nãoferrosos - alumínio presente em latas de bebidas e cobre que constituem os cabos telefônicos e enrolamentos elétricos; os metais pesados - o níquel, zinco e mercúrio.

Segundo Jardim (1995), o principal objetivo da reciclagem é reintegrar os materiais recicláveis como substitutos de matérias-primas na fabricação de outros produtos que permite geração de uma economia que é obtida pelo diferencial de preços entre as matérias virgens e as matérias recicladas.

A preservação de recursos naturais encontra na reciclagem uma maneira de realizar uma minimização no uso desses recursos, pois faz o reaproveitamento e a reutilização dos materiais já existentes diminuindo a necessidade de extração de matéria prima in natura.

\subsection{Educação Ambiental}

Para Dias (2004), o processo de Educação Ambiental procura fazer com que as pessoas adquiram consciência do ambiente à sua volta e almejem a busca pelo conhecimento, valores, e experiências que os tornem capazes de solucionar problemas ambientais no presente e no futuro. 
As características de uma Educação Ambiental são: o enfoque orientado a solução de problemas concretos da comunidade; o enfoque multidisciplinar; e a participação da comunidade em caráter permanente, orientada para o futuro.

A Educação Ambiental segundo a Lei n.o $9795 / 99$ pode ser definida:

\begin{abstract}
Art. 10 Entendem-se por educação ambiental os processos por meio dos quais o indivíduo e a coletividade constroem valores sociais, conhecimentos, habilidades, atitudes e competências voltadas para a conservação do meio ambiente, bem de uso comum do povo, essencial à sadia qualidade de vida e sua sustentabilidade. Art. 20 A educação ambiental é um componente essencial e permanente da educação nacional, devendo estar presente, de forma articulada, em todos os níveis e modalidades do processo educativo, em caráter formal e não-formal.
\end{abstract}

Dias (2004) afirma que a Educação Ambiental não é apenas uma forma de educação, e sim uma ferramenta para solucionar os problemas relacionados ao meio ambiente. $O$ processo de Educação Ambiental deve prover os meios de percepção e compreensão dos diversos fatores que fazem parte da integração do tempo e do espaço a fim e modelar e preservar o meio ambiente através de iniciativas simples que podem sem implantadas no dia a dia.

A ação da prática da Educação Ambiental tem como objetivo principal a mudança do indivíduo através da realização do desenvolvimento de novos valores, hábitos, condutas e atos na relação com o meio ambiente, através de atividades simples do cotidiano dentre elas: a redução na geração de resíduos, a realização da coleta seletiva, a reciclagem e a conservação de recursos naturais do meio ambiente.

\title{
3 CONSIDERAÇÕES FINAIS
}

O gerenciamento adequado dos resíduos sólidos produzidos pela população inclui a sua redução, reutilização e reciclagem, tornando o processo construtivo mais rentável e competitivo, além de mais saudável.

Através da coleta seletiva é possível o desenvolvimento de uma maior consciência ambiental e dos princípios de cidadania da população. A Educação 
Ambiental é o principal meio para se propagar a conscientização das pessoas quanto aos problemas relacionados ao lixo, e como consequência mudar as formas de consumo e utilização de bens duráveis e não duráveis que a cada dia aumenta a geração de resíduos, bem como a poluição ambiental.

Ao inserir a Educação Ambiental de forma a informar os processos de coleta seletiva, consegue-se atingir diversas áreas da sociedade, como empresas, associações, repartições públicas, entre outras. Dessa forma é possível que a população sensibilize-se e mude seus hábitos de consumo ao criar novos valores em relação à preservação ambiental.

A disposição final dos resíduos sólidos deve ser analisada com cautela pois não se trata de um fato isolado, isto posto se não tiver o seu devido tratamento seus efeitos podem ser drásticos como poluição do solo, lençóis freáticos, não se restringindo apenas aos centros urbanos.

\section{REFERÊNCIAS BIBLIOGRÁFICAS}

ABNT NBR 10004. Resíduos Sólidos - classificação. Disponível em: <http://www.aslaa.com.br/legislacoes/NBR\%20n\%2010004-2004.pdf>. Acesso em: 21 nov. 2013.

BARTOLOMEU, D. B.; CAIXEITA-FILHO, J. V. Logística ambiental de resíduos sólidos. São Paulo: Atlas, 2011.

BIDONE, F. R. A.; POVINELLI, J. Conceitos básicos de resíduos sólidos. São Carlos: EESC/USP, 1999.

BRASIL. Lei no 9.795, de 27 de abril de 1999. Dispõe sobre a educação ambiental, institui a Política Nacional de Educação Ambiental e dá outras providências. Disponível em:

<http://www.planalto.gov.br/ccivil_03/Leis/L9795.htm/ >. Acesso em: 21 nov. 2013.

CEMPRE. Compromisso Empresarial para Reciclagem. Disponível em: <http://www.cempre.org.br/biblioteca.php>. Acesso em: 21 nov. 2013.

DIAS, G. F. Educação Ambiental: Princípios e Praticas. São Paulo: Gaia, 2004.

JARDIM, N. S. Lixo Municipal: manual de gerenciamento integrado. São Paulo: Instituto de Pesquisas Tecnológicas (IPT) e Compromisso Empresarial para Reciclagem (CEMPRE), 1995.

MANSOR, M. T. C. et al. Caderno de Educação Ambiental: resíduos sólidos. São Paulo: Secretaria do Meio Ambiente, 2010.

MIRANDA, L. L. O que é Lixo. São Paulo: Brasiliense, 1995. 
PAULA, M. B.; SOUZA-PINTO, H. A Importância das Cooperativas de Reciclagem na

Consolidação dos Canais Reversos de Resíduos Sólidos. 2010. 16f. Simpoi - Anais. 2010.

Disponível: em <www.simpoi.fgvsp.br/arquivo/2010/>. Acesso em: 21 nov. 2013.

PNSB. Pesquisa Nacional de Saneamento Básico. Disponível em:

<http://www.ibge.gov.br/home/estatistica/populacao/condicaodevida/pnsb2008/PNSB2008.pdf>. Acesso em: 21 nov. 2013.

SÃO PAULO. Secretaria do Meio Ambiente. Coordenadoria de Educação Ambiental. Cadernos de Educação Ambiental: Resíduos Sólidos. São Paulo, 2010.

SÃO PAULO. Secretaria do Meio Ambiente. Coordenadoria de Educação Ambiental. Cadernos de Educação Ambiental: Guia Pedagógico do Lixo. São Paulo, 2010.

SÃO PAULO. Secretaria do Meio Ambiente. Coleta Seletiva: na escola, no condomínio, na comunidade e no município. São Paulo, 2007.

SANTOS, Z. Coleta Seletiva e Responsabilidade Social: O Caso da Cooperativa de Reciclagem Trabalho e Produção - CORTRAP. 2011. 47f. Dissertação (Especialização em Gestão Ambiental) Faculdade Integrada da Grande Fortaleza. Fortaleza. Disponível em:

<http://bd.camara.gov.br/bd/bitstream/handle/bdcamara/6565/coleta_seletiva_santos.pdf?sequence=1 >. Acesso em: 21 nov. 2013.

SEBRAE. Serviço Brasileiro de Apoio às Micro e Pequenas Empresas. Disponível em: <http://www.sebraemg.com.br/culturadacooperacao/associacoes/05.htm>. Acesso em: 21 nov. 2013. 